\title{
ANALISIS PERILAKU KONSUMEN DALAM PEMBELIAN BUAH DURIAN DI KOTA MATARAM
}

\author{
CONSUMER BEHAVIOUR ANALISYS IN PURCHASING \\ DURIAN FRUITS IN MATARAM CITY
}

\author{
Anak Agung Istri Kris Paridewi, I Ketut Budastra dan Addinul Yakin \\ Program Studi Agribisnis Fakultas Pertanian Universitas Mataram
}

\begin{abstract}
ABSTRAK
Penelitian ini bertujuan untuk (1) menganalisis perilaku konsumen dalam pembelian buah durian; (2) menganalisis tingkat kepuasan konsumen terhadap atribut-atribut buah durian. Penelitian ini menggunakan metode deskiptif. Penentuan lokasi sampel dilakukan dengan metode purposive sampling dan penentuan responden dilakukan secara quota sampling. Penelitian dilakukan di Kota Mataram. Analisis data yang digunakan diantaranya adalah analisis TRA (The Theory of Reasoned-Action), dan CSI (Customer Satisfaction Index). Hasil penelitian menunjukkan bahwa: (1) Perilaku konsumen dalam pembelian buah durian di Kota Mataram menunjukkan hasil yaitu 3,57 dalam arti konsumen kemungkinan akan membeli kembali buah durian tersebut, keputusan konsumen membeli di dominasi oleh atribut cita rasa karna cita rasa dari buah durian tersebut menjadi alasan utama dalam memutuskan pembelian dengan memiliki nilai evaluasi paling tinggi dibandingkan atribut lainnya dan motivas referen yang dipercayai oleh konsumen lebih mengikuti anjuran dari pihak keluarga (2) Perilaku konsumen berdasarkan karakteristik responden menurut pekerjaan, pendapatan dan suku/etnik rata-rata menunjukkan hasil yang positif dalam arti tidak adanya perbedaan perilaku konsumen dalam mengambil keputusan membeli buah durian di Kota Mataram (3) Kepuasan konsumen dalam pembelian buah durian di Kota Mataram termasuk dalam kategori tinggi dengan perhitungan Customer Satisfaction Index (CSI) sebesar 0,72 atau $72 \%$ termasuk dalam kategori bahwa konsumen merasa puas terhadap atribut-atribut buah durian berikut: harga, ukuran, tekstur, aroma, cita rasa, warna, kesegaran, kebersihan dan jenis durian, karena berada pada indeks antara 0,66 sampai 0,88 .
\end{abstract}

Kata Kunci : Perilaku Konsumen, Kepuasan Konsumen, Buah Durian.

\section{ABSTRACT}

This research aims to (1) analyze consumer behavior in the purchase of durian fruit; (2) analyze the level of customer satisfaction with the attributes of durian fruit. This research uses the descriptive method, data analisys include analisys of TRA (Theory of Reasoned Action) and CSI (Customer Satisfaction Index). The determination of location was done by purposive 
sampling method and the determination of respondents was done by quota sampling. The results showed that: (1) Consumer behavior in purchasing durian showed a result of 3,57 in the sense that consumers would likely to repurchsase the durian fruit, the decision of consumers to buy was dominated by taste of the durian fruit and referrals family (2) Respondents characteristics (job, income and ethnic) shows positive but insignificant relationship to consumer buying behaviors (3) Consumer satisfaction in purchasing durian in Mataram city is high category with the calculation of the Customer Satisfactin Index (CSI) of 0,72 . This means $72 \%$ of the consumers are satisfied with the durians attributes, such as the price, size, texture, flavor, taste, color, freshness, cleanliness and type of durian.

Key Words : Consumer Behavior, Customer Satisfaction, Durian Fruit

\section{PENDAHULUAN}

Salah satu jenis buah-buahan yang banyak dibudidayakan di Nusa Tenggara Barat adalah buah durian (Durio zibethinus). Tanaman durian merupakan tanaman buah tropika yang sangat populer dan dijuluki sebagai raja buah. Durian merupakan salah satu jenis buah-buahan yang bergizi tinggi dan mempunyai peluang besar untuk dikembangkan. Selain mempunyai aroma yang khas dan berasa lezat, buah durian juga mempunyai kandungan gizi yang relatif lengkap dibandingkan buah-buahan lainnya.

Buah durian merupakan buah yang paling primadona diantara buah lainnya, digemari oleh masyarakat luas yang ada di Lombok Khususnya Kota Mataram karna saat musim durian telah tiba dan pada saat itu konsumen gencar untuk mencari, membeli dan menikmati kelezatan dari buah durian tersebut. Secara teoritis, setiap konsumen yang telah mengkonsumsi buah durian memiliki pandangan ataupun persepsi yang berbeda terhadap atribut buah durian tersebut seperti harga buah durian, kondisi kesegaran, aroma, tekstur, cita rasa, ukuran, warna, kebersihan, dan jenis buah durian sehingga pada akhirnya dapat mempengaruhi konsumen dalam melakukan keputusan pembelian. Selain itu umur, jenis kelamin dan selera konsumen yang beragam serta kebutuhan yang harus dipenuhi oleh setiap rumahtangga, mempengaruhi perilaku konsumen.

Pentingnya mengetahui perilaku konsumen buah durian di Kota Mataram, yaitu agar buah durian yang ditawarkan bisa laku terjual dalam jumlah yang banyak serta untuk mengambil keputusan buah durian mana yang harus di sediakan dalam jumlah yang lebih besar, selain itu studi perilaku konsumen sangat penting untuk mengambil keputusan dalam memilih strategi pemasaran agar pemasaran buah durian berjalan dengan lancar dan mudah laku di pasaran.

Penelitian ini bertujuan : (1) Untuk mengetahui perilaku konsumen dalam pembelian buah durian di Kota Mataram, (2) Untuk mengetahui tingkat kepuasan konsumen terhadap atribut-atribut buah durian di Kota Mataram. 


\section{METODOLOGI PENELITIAN}

Metode yang digunakan dalam penelitian ini yaitu metode deskriptif. Unit analisis dalam penelitian ini adalah konsumen perseorangan di Kota Mataram. Penentuan lokasi penelitian ditentukan dengan teknik purposive sampling atau dilakukan dengan sengaja di sentra penjualan buah durian di Kota Mataram yaitu di Kelurahan Selagalas. Penentuan jumlah sampel konsumen ditentukan dengan teknik "quota sampling sebanyak 40 responden, dimana secara keseluruhan konsumen yang diambil sebagai responden adalah konsumen buah durian di sentra penjualan buah durian di Kelurahan Selagalas. Pengambilan sampel yang dilakukan dalam penelitian ini menggunakan accidental sampling, yaitu siapa saja yang secara kebetulan bertemu dengan peneliti dan bersedia diwawancarai. Jenis data yang digunakan dalam penelitian ini adalah data kuantitatif dan kualitatif. Sumber data yang digunakan dalam penelitian ini adalah data primer dan data sekunder. Variabel dan cara pengukuran menggunakan Analisis Fishbein model TRA (The Theory of Reasoned-Action) dengan 2 variabel yaitu variabel sikap konsumen (Ab) dan variabel norma subyektif (SN) sebagai pertimbangan konsumen untuk membeli buah durian dan untuk mengetahui tingkat kepuasan konsumen terhadap atribut-atribut buah durian menggunakan analisis CSI (Customer Satisfaction Index). Dalam penelitian ini jawaban setiap pertanyaan mengenai perilaku konsumen menggunakan skala likert yang terdiri dari 5 tingkatan yaitu: (5) Sangat setuju, (4) Setuju, (3) Netral/Biasa saja (2) Tidak setuju dan (1) Sangat tidak setuju.

\section{Analisis Sikap Konsumen (Ab)}

Untuk mengetahui pengaruh sikap konsumen $(\mathrm{Ab})$ terhadap atribut buah impor dalam menentukan perilaku konsumen untuk membeli, digunakan analisis model Fishbein sebagai berikut :

$$
\mathbf{A b}=\sum_{\mathbf{i}=\mathbf{1}}^{\mathbf{n}} \mathbf{b}_{\mathbf{i}} \mathbf{e}_{\mathbf{i}}
$$

Keterangan :

$\mathrm{Ab}=$ Sikap total individu terhadap atribut buah durian.

$\mathrm{b}_{\mathrm{i}} \quad=$ Kekuatan keyakinan konsumen terhadap atribut buah durian (Skor i $=1,2,3,4,5)$.

$\mathrm{e}_{\mathrm{i}} \quad=$ Evaluasi terhadap atribut buah durian (Skor $\left.\mathrm{i}=1,2,3,4,5\right)$.

\section{Analisis Norma Subyektif (SN)}

Untuk mengetahui pengaruh norma subyektif (SN) yang timbul dari referen (teman dan keluarga) berdampak terhadap perilaku pembelian konsumen terhadap buah durian di Kota Mataram menggunakan rumus sebagai berikut: 


$$
\mathrm{SN}=\sum_{\mathrm{i}=1}^{\mathrm{n}} \mathrm{NB}_{\mathrm{i}} \mathrm{MC}_{\mathrm{i}}
$$

$\mathrm{SN} \quad=$ Norma Subyektif

$\mathrm{NB}_{\mathrm{j}} \quad=$ Keyakinan normatif individu (Skor 1, 2, 3, 4, 5)

$\mathrm{MC}_{\mathrm{j}}=$ Motivasi dari referen (Skor 1, 2, 3, 4, 5)

\section{Analisis Perilaku Konsumen}

Berdasarkan sikap konsumen dan norma subyektif konsumen, digunakan persamaan sebagai berikut (Umar dalam Danang Sunyonto, 2014):

Keterangan :

$$
\mathrm{B} \sim \mathrm{BI}=\mathrm{W}_{1}(\mathrm{Ab})+\mathrm{W}_{2}(\mathrm{SN})
$$

B $\quad=$ Perilaku konsumen (behavior intention)

$\mathrm{BI} \quad=$ Maksud perilaku

$\mathrm{AB}=$ Sikap total individu terhadap atribut buah durian.

$\mathrm{SN} \quad=$ Norma subjektif

$\mathrm{W}_{1} \mathrm{~W}_{2}=$ Bobot yang ditemukan secara empiris, menggambarkan pengaruh relatif komponen. Jika pengambilan keputusan lebih banyak dilakukan oleh konsumen sendiri, maka nilai $W_{1}>W_{2}$. Sebaliknya, jika pengambilan keputusan lebih banyak dilakukan karena pengaruh pihak lain, maka $\mathrm{W}_{1}<$ $\mathrm{W}_{2}$.

Interpretasi skor Perilaku konsumen dapat ditentukan denga menggunakan skala interval yang rumusnya adalah:

$$
\text { Skala }=\frac{(\mathbf{m}-\mathbf{n})}{\mathbf{b}}
$$

$\mathrm{n}=$ Skor terendah yang mungkin per atribut

$\mathrm{m}=$ Skor tertinggi yang mungkin per atribut

$\mathrm{b}=$ Jumlah skala penilaian yang ingin dibentuk (jumlah kelas)

Maka interval skor untuk perilaku konsumen adalah :

$$
\text { Skala interval }=\frac{(5-1)}{5}=0,8
$$

Maka skor Perilaku Konsumen (B $\mathrm{BI})$ dapat dilihat dalam tabel berikut : Tabel skor Perilaku Konsumen

\begin{tabular}{ll}
\hline Skor norma perilaku (B B $)$ & Interpretasi \\
\hline$(1,0) \leq \mathrm{BI} \leq(1,79)$ & Pasti Tidak \\
$(1,80) \leq \mathrm{BI} \leq(2,59)$ & Kemungkinan Tidak \\
$(2,60) \leq \mathrm{BI} \leq(3,39)$ & Netral \\
$(3,40) \leq \mathrm{BI} \leq(4,19)$ & Kemungkinan $\mathrm{Ya}$ \\
$(4,20) \leq \mathrm{BI} \leq(5,0)$ & Pasti Ya \\
\hline
\end{tabular}


Apabila nilai $\mathrm{B} \sim \mathrm{BI}$ berada pada rentang $(4,20) \leq \mathrm{BI} \leq(5,0)$ maka perilaku pembelian konsumen terhadap buah durian di Kota Mataram dikategorikan baik (Positif akan membeli kembali). Namun jika diperoleh nilai $\mathrm{B} \sim \mathrm{BI}$ berada pada rentang $(1,0) \leq \mathrm{BI} \leq(1,79)$, maka perilaku konsumen dapat dikategorikan tidak baik (tidak akan membeli kembali) terhadap buah durian di Kota Mataram.

\section{Customer Satisfaction Index (CSI)}

Metode Customer Satisfaction Index (CSI) digunakan untuk menentukan tingkat kepuasan konsumen buah duriansecara menyeluruh dengan pendekatan yang mempertimbangkan tingkat kepuasan atribut-atribut yang diukur. Metode pengukuran CSI ini meliputi tahap-tahap berikut (Stratford, 2004) :

1. Menentukan Mean Satisfaction Score (MSS)

MSS merupakan nilai rata-rata tingkat kinerja yang dirasakan konsumen tiap variable atribut, MSS dapat dihitung dengan menggunakan rumus sebagai berikut:

$$
\text { MSS }=\frac{\sum_{i=1}^{n} X i}{\mathbf{n}}
$$

Keterangan :

$\mathrm{n}=$ Jumlah responden

$\mathrm{X}=$ = Nilai kinerja atribut ke- $\mathrm{i}$

2. Menentukan Mean Importance Score (MIS)

Mean Importance Score (MIS) merupakan nilai rata-rata tingkat kepentingan konsumen tiap variabel atau atribut yang dapat dihitung dengan menggunakan:

$$
\text { MIS }=\frac{\sum_{i=1}^{n} Y i}{\mathbf{n}}
$$

Keterangan :

$\mathrm{n}$ = Jumlah responden

$\mathrm{Yi}=$ Nilai kepentingan atribut ke-i

\section{Wighting Factor (WF)}

Bobot ini merupakan nilai MIS per atribut terhadap total MIS seluruh atribut yang diuji.

$$
\mathbf{W F} i=\frac{\text { MIS } i}{\sum_{i=1}^{p} \text { MISi } i}
$$

4. Weighted Score (WS)

Fungsi dariWeighting Factor (WF) dikalikan dengan Mean SatisfactionScore berdasrkan tiap-tiap atribut.

$$
\text { WS } i=\text { WF } i \times \text { MSS } i
$$

5. Customer Satisfaction Index (CSI)

Nilai yang diperoleh dari perhitungan CSI digunakan untuk mengetahui tingkat kepuasan pengunjung. Dihitung dengan rumus : 


$$
C S I=\frac{\sum_{i=1}^{p} W S i}{\text { Lebar skala yang digunakan }} \times 100
$$

Pada umumnya, bila nilai CSI diatas $50 \%$ atau sebesar 0,50 maka dapat dikatakan bahwa konsumen sudah merasa puas terhadap suatu produk. Sebaliknya jika nilai CSI dibawah 50\% atau sebesar 0,50 maka dapat dikatakan konsumen belum puas terhadap suatu produk tertentu. Nilai CSI ini dibagi dalam lima kriteria, mulai dari tidak puas sampai dengan sangat puas, kriterianya sebagai berikut.

\begin{tabular}{cc}
\hline Nilai Indeks & Kriteria Kepuasan Konsumen \\
\hline $0.81-1.00$ & Sangat Puas \\
$0.66-0.80$ & Puas \\
$0.51-0.65$ & Cukup Puas \\
$0.35-0.50$ & Kurang Puas \\
$0.00-0.34$ & Tidak Puas \\
\hline
\end{tabular}

Sumber : Wildan, 2005

\section{HASIL DAN PEMBAHASAN}

\section{Karakteristik Responden}

Karakteristik responden yang dibahas dalam penelitian ini meliputi umur, tingkat pendidikan, pekerjaan, pendapatan dan suku/etnik.

\begin{tabular}{|c|c|c|}
\hline \multicolumn{3}{|l|}{ KarakteristikResponden } \\
\hline Kisaran Umur (thn) & Jumlah (org) & Persentase (\%) \\
\hline Dewasa Awal (19-20 tahun) & 1 & 2,5 \\
\hline Dewasa Lanjut (21-35 tahun) & 18 & 45 \\
\hline Paruh Baya (36-50 tahun) & 17 & 42,5 \\
\hline Tua (51-60) & 4 & 10 \\
\hline Jumlah & 40 & 100 \\
\hline \multicolumn{3}{|l|}{ Tingkat Pendidikan } \\
\hline SMP & 2 & 5 \\
\hline SMA/SMK & 20 & 50 \\
\hline Diploma & 1 & 2,5 \\
\hline S1 & 15 & 37,5 \\
\hline S2 & 2 & 5 \\
\hline Jumlah & 40 & 100 \\
\hline \multicolumn{3}{|l|}{ Pekerjaan } \\
\hline IRT & 3 & 7,5 \\
\hline Mahasiswa & 4 & 10 \\
\hline PNS & 13 & 32,5 \\
\hline Pegawai Swasta & 7 & 17,5 \\
\hline Wiraswasta & 8 & 20 \\
\hline $\begin{array}{l}\text { DIl (Perangkat desa, konsultan, } \\
\text { Staff, buruh) }\end{array}$ & 5 & 12,5 \\
\hline Jumlah & 40 & 100 \\
\hline
\end{tabular}




\begin{tabular}{|l|c|c|}
\hline Pendapatan \\
\hline Rp.500.000,00-Rp. 1.000.000,00 & 5 & 12,5 \\
\hline Rp.1.000.000,00-Rp.2.500.000,00 & 8 & 20 \\
\hline Rp.2.500.000,00-Rp.5.000.000,00 & 23 & 57,5 \\
\hline > Rp. 5.000.000 & 4 & 10 \\
\hline Jumlah & $\mathbf{4 0}$ & $\mathbf{1 0 0}$ \\
\hline Suku/Etnis & 23 & 57,5 \\
\hline Sasak & 5 & 12,5 \\
\hline Samawa & 5 & 12,5 \\
\hline Mbojo & 3 & 7,5 \\
\hline Bali & 4 & 10 \\
\hline Jawa & $\mathbf{4 0}$ & $\mathbf{1 0 0}$ \\
\hline Jumlah & &
\end{tabular}

Berdasarkan tabel karakteristik responden diatas dapat diketahui bahwa umur responden peminat durian terbanyak pada kisaran umur 21-35 tahun yaitu sebanyak 18 orang $(45 \%)$, tingkat pendidikan responden terbanyak pada tingkat SMA yaitu sebanyak 20 orang (50\%), jenis pekerjaan responden terbanyak pada PNS yaitu sebanyak 13 orang (32,5\%), jumlah pendapatan responden terbanyak pada kisaran Rp. 2.500.000-Rp. 5.000.000 yaitu sebanyak 23 orang $(57,5 \%)$ dan suku/etnik responden terbanyak pada suku sasak yaitu sebanyak 23 orang $(57,5 \%)$.

\section{Perilaku Konsumen dalam Pembelian Buah Durian di Kota Mataram}

Model perilaku konsumen yang digunakan dalam penelitian ini yaitu analisis perilaku menggunakan TRA (The Theory of Reasoned-Action) yang merupakan bagian dari model sikap multiatribut fishbein. Model TRA (The Theory of Reasoned-Action), menerangkan bahwa perilaku dipengaruhi oleh minat berperilaku. Minat berperilaku terdiri dari komponen sikap (Ab) dan Norma Subyektif (SN). Berikut hasil perhitungan perilaku konsumen disajikan pada tabel 1.

Tabel 1. Hasil Perhitungan Perilaku Konsumen dalam Pembelian Buah Durian di Kota Mataram

\begin{tabular}{|c|c|c|}
\hline \multicolumn{2}{|c|}{ No Komponen } & Interval Skor \\
\hline 1 & Sikap (Ab) & 3,65 Positif \\
\hline & $\square \quad$ Keyakinan (bi) & 3,71 Positif \\
\hline & $\square \quad$ Evaluasi (ei) & 3,60 Positif \\
\hline 2 & Norma Subjektif (SN) & 3,49 Positif \\
\hline & $\square \quad$ Keyakinan Normatif ( NBj) & 3,50 Positif \\
\hline & $\square \quad$ Motivasi Mengikuti (MCj) & 3,48 Positif \\
\hline 3 & Bobot Empiris & \\
\hline & $\square$ Bobot Empiris Sikap (W1) & 0,51 \\
\hline & $\square$ Bobot Empiris Norma Subyektif (W2) & 0,49 \\
\hline 4 & Perilaku Konsumen & 3,57 Kemungkinan ya (Positif) \\
\hline
\end{tabular}

Sumber: Data Primer diolah, 2019 
Berdasarkan Tabel 1 menunjukkan bahwa secara parsial rata-rata nilai bi dan ei masing-masing sebesar 3,71 dan 3,60 yang keduanya berada pada interval skor positif, setelah total skor total bi dan ei dijumlahkan kemudian dirata-ratakan, secara bersama-sama menghasilkan nilai sikap sebesar 3,65 yang berada pada interval skor positif. Begitu juga dengan perhitungan Norma Subyektif, setelah total skor NBj dan MCj dijumlahkan kemudian dirataratakan, secara bersama-sama menghasilkan norma subjektif sebesar 3,49 yang berada pada interval skor positif. Nilai W1 dan W2 yaitu sebesar 0,51 dan 0,49 yang diperoleh dari perhitungan bobot empiris GMAb dan GMSN yang menunjukkan bahwa pembelian konsumen lebih didominasi oleh diri sendiri dibandingkan orang lain yang terlihat dari nilai W1 lebih besar dibandingkan dengan W2. Selanjutnya perilaku konsumen bernilai 3,57 yang berada pada interval perilaku yang kemungkinan akan membeli lagi buah durian di Kota Mataram, nilai perilaku konsumen diperoleh dari skor sikap dan norma subyektif masing-masing variabel dikalikan dengan bobot sikap (W1) dan bobot norma subyektif (W2).

Tabel 2. Sikap Konsumen (Ab) dalam Pembelian Buah Durian di Kota Mataram

\begin{tabular}{clllll}
\hline No & Atribut Produk & Bi & Ei & Ab & Interpretasi Skor \\
\hline 1 & Harga & 3,38 & 3,20 & 3,29 & Netral $(2,60) \leq A b \leq(3,39)$ \\
2 & Ukuran & 3,70 & 3,60 & 3,65 & Positif $(3,40) \leq A b \leq(4,19)$ \\
3 & Tekstur & 3,78 & 3,63 & 3,70 & Positif $(3,40) \leq A b \leq(4,19)$ \\
4 & Aroma & 4,10 & 3,98 & 4,04 & Positif $(3,40) \leq A b \leq(4,19)$ \\
5 & Cita rasa & 4,18 & 4,08 & 4,13 & Positif $(3,40) \leq A b \leq(4,19)$ \\
6 & Warna & 3,40 & 3,35 & 3,37 & Netral $(2,60) \leq A b \leq(3,39)$ \\
7 & Kesegaran & 3,55 & 3,48 & 3,51 & Positif $(3,40) \leq A b \leq(4,19)$ \\
8 & Kebersihan & 3,65 & 3,55 & 3,60 & Positif $(3,40) \leq A b \leq(4,19)$ \\
9 & Jenis durian & 3,68 & 3,58 & 3,63 & Positif $(3,40) \leq A b \leq(4,19)$ \\
\hline \multicolumn{7}{c}{ Nilai Sikap Konsumen } & & $\mathbf{3 , 6 5}$ & Positif $(\mathbf{3 , 4 0} \leq \mathrm{Ab} \leq(\mathbf{4 , 1 9})$ \\
\hline
\end{tabular}

Sumber : Data primer diolah, 2019

Hasil penelitian menunjukkan sikap konsumen dalam pembelian buah durian di Kota Mataram bernilai 3,65 yang berada pada interval skor sikap $(3,40) \leq A b \leq(4,19)$ dalam arti konsumen memiliki sikap positif dalam pembelian buah durian di Kota Mataram didasarkan pada variabel keyakinan (bi) dan variabel evaluasi (ei) konsumen terhadap atribut yang diteliti secara keseluruhan. Keyakinan dan evaluasi konsumen dalam pembelian buah durian menentukan sikap konsumen terhadap keputusan membeli dan mengkonsumsi. Berikut hasil perhitungan variabel keyakinan (bi) dan evaluasi (ei). 
Tabel 3. Norma Subyektif (SN) Konsumen dalam Pembelian Buah Durian di Kota Mataram

\begin{tabular}{llcrc}
\hline No. & Referen & NBj & MCj & SN \\
\hline 1 & Teman & 3,38 & 3,38 & 3,38 \\
2 & Keluarga & 3,63 & 3,58 & 3,60 \\
\hline \multicolumn{2}{c}{ Rata-Rata Nilai Norma Subyektif } \\
\end{tabular}

Sumber: Data primer diolah, 2019

Norma Subyektif konsumen bernilai 3,49 yang berada pada interval skor Norma Subyektif $(3,40) \leq \mathrm{SN} \leq(4,19)$ dalam arti referen (teman dan keluarga) menganjurkan responden untuk membeli. Keputusan pembelian buah durian di Kota Mataram didasarkan pada variabel keyakinan Normatif (NBj) dan Variabel Motivasi (MCj) sebagai pengaruh eksternal selain kemauan dari diri responden. Berikut hasil perhitungan variabel Keyakinan Normatif (NBj) dan Variabel Motivasi (MCj).

\section{Analisis Perilaku Konsumen (B BI) dalam Pembelian Buah Durian di Kota Mataram}

Sebagaimana model fishbein, hubungan antara komponen dalam model fishbein dapat dikatakan bahwa perilaku adalah maksud dari fungsi perilaku dan faktor lain yang mempengaruhi. Dengan kata lain perbuatan adalah fungsi dari keinginan untuk berbuat yang telah terbentuk sebelumnya dan faktor situasional yang mempengaruhi subjek.

Berdasarkan hasil perhitungan nilai sikap, norma subyektif, hingga perhitungan bobot empiris pengaruh relatif komponen (W1 dan W2) maka perilaku konsumen sesuai dengan TRA (The Theory of Reasoned Action) sebagai berikut:

$$
\begin{aligned}
\mathbf{B} \sim \mathbf{B I} & =\mathbf{W} \mathbf{1}(\mathbf{A b})+\mathbf{W} \mathbf{2}(\mathbf{S N}) \\
& =0,51(3,65)+0,49(3,49) \\
& =1,86+1,71 \\
& =3,57
\end{aligned}
$$

Nilai B BI adalah $(3,57)$ maka dapat dikatakan bahwa konsumen mempunyai perilaku membeli positif artinya konsumen kemungkinan ya akan membeli kembali buah durian di Kota Mataram setelah pembelian pertama berdasarkan hasil perhitungan sikap (Ab) dan Norma Subjektif (SN). 
Tabel 4. Perilaku Konsumen (B BI) dalam Pembelian Buah Durian di Kota Mataram Berdasarkan Pekerjaan

\begin{tabular}{lccccc}
\hline Uraian & Sikap (Ab) & $\begin{array}{c}\text { W1 } \\
\text { (Bobot } \\
\text { Ab) }\end{array}$ & $\begin{array}{c}\text { Norma } \\
\text { Subyektif } \\
\text { (SN) }\end{array}$ & $\begin{array}{c}\text { W2 } \\
\text { (Bobot } \\
\text { SN) }\end{array}$ & $\begin{array}{c}\text { Perilaku } \\
\text { Konsumen } \\
\text { (B BI) }\end{array}$ \\
\hline IRT & 4.03 & 0.52 & 3.74 & 0.48 & 3.8908 \\
Mahasiswa & 3.76 & 0.52 & 3.50 & 0.48 & 3.6352 \\
PNS & 3.59 & 0.50 & 3.55 & 0.50 & 3.5700 \\
Pegawai Swasta & 3.70 & 0.51 & 3.56 & 0.49 & 3.6314 \\
Wiraswasta & 3.55 & 0.52 & 3.34 & 0.48 & 3.4492 \\
DLL & 3.54 & 0.52 & 3.25 & 0.48 & 3.4008 \\
\hline
\end{tabular}

Sumber : Data primer diolah, 2019

Dari tabel diatas nilai $B \sim B \mid$ menurut pekerjaan secara keseluruhan dapat dikatakan bahwa konsumen mempunyai perilaku membeli positif artinya konsumen kemungkinan akan membeli kembali buah durian di Kota Mataram setelah pembelian pertama berdasarkan hasil perhitungan sikap (Ab) dan Norma Subjektif (SN).

Tabel 5. Perilaku Konsumen (B BI) dalam Pembelian Buah Durian di Kota Mataram Berdasarkan Pendapatan

\begin{tabular}{lrrrrr}
\hline Uraian & Sikap (Ab) & $\begin{array}{c}\text { W1 } \\
\text { (Bobot } \\
\text { Ab) }\end{array}$ & $\begin{array}{c}\text { Norma } \\
\text { Subyektif } \\
\text { (SN) }\end{array}$ & $\begin{array}{c}\text { W2 } \\
\text { (Bobot } \\
\text { SN) }\end{array}$ & $\begin{array}{c}\text { Perilaku } \\
\text { Konsumen } \\
(\mathrm{B} \sim \mathrm{BI})\end{array}$ \\
\hline $500-1 \mathrm{jt}$ & 3.76 & 0.51 & 3.6 & 0.49 & 3.6816 \\
$1 \mathrm{jt}-2.5 \mathrm{jt}$ & 3.63 & 0.51 & 3.52 & 0.49 & 3.5761 \\
$2.5 \mathrm{jt}-5 \mathrm{jt}$ & 3.64 & 0.51 & 3.45 & 0.49 & 3.5469 \\
$>5 \mathrm{jt}$ & 3.6 & 0.51 & 3.43 & 0.49 & 3.5167 \\
\hline
\end{tabular}

Sumber : Data primer diolah, 2019

Dari tabel diatas nilai $\mathrm{B} \sim \mathrm{BI}$ menurut pendapatan secara keseluruhan dapat dikatakan bahwa konsumen mempunyai perilaku membeli positif artinya konsumen kemungkinan akan membeli kembali buah durian di Kota Mataram setelah pembelian pertama berdasarkan hasil perhitungan sikap (Ab) dan Norma Subjektif (SN).

Tabel 6. Perilaku Konsumen $(\mathrm{B} \sim \mathrm{BI})$ dalam Pembelian Buah Durian di Kota Mataram Berdasarkan Suku/Etnis

\begin{tabular}{lrrrrr}
\hline Uraian & Sikap (Ab) & \multicolumn{1}{c}{$\begin{array}{c}\text { W1 } \\
\text { (Bobot } \\
\text { Ab) }\end{array}$} & $\begin{array}{c}\text { Norma } \\
\text { Subyektif } \\
\text { (SN) }\end{array}$ & $\begin{array}{c}\text { W2 } \\
\text { (Bobot } \\
\text { SN) }\end{array}$ & $\begin{array}{c}\text { Perilaku } \\
\text { Konsumen (B BI) }\end{array}$ \\
\hline Sasak & 3.59 & 0.51 & 3.46 & 0.49 & 3.5263 \\
Samawa & 3.77 & 0.52 & 3.5 & 0.48 & 3.6404 \\
Mbojo & 3.52 & 0.49 & 3.65 & 0.51 & 3.5863 \\
Bali & 3.9 & 0.52 & 3.58 & 0.48 & 3.7464 \\
Jawa & 3.83 & 0.53 & 3.31 & 0.47 & 3.5856 \\
\hline
\end{tabular}


Dari Tabel 6 nilai B BI menurut suku/etnis secara keseluruhan dapat dikatakan bahwa konsumen mempunyai perilaku membeli positif artinya konsumen kemungkinan akan membeli kembali buah durian di Kota Mataram setelah pembelian pertama berdasarkan hasil perhitungan sikap (Ab) dan Norma Subjektif (SN).

\section{Indeks Kepuasan Konsumen}

Costumer Satisfaction Index (CSI) digunakan untuk mengetahui tingkat kepuasan konsumen secara menyeluruh berdasarkan tingkat kepentingan dari atribut-atribut buah durian, sehingga kepuasan konsumen terhadap buah durian yang dibeli dari pedagang dapat diketahui nilainya. Perhitungan Costumer Satisfaction Index (CSI) menggunakan nilai skor rata-rata tingkat kepentingan dan tingkat kinerja dari masing-masing atribut dengan menghitung nilai Mean Importance Score (MIS), Mean Satisfaction score (MSS), Wighting Factor (WF), Weighted Score (WS). Berikut hasil perhitungannya, dapat dilihat pada tabel 7 berikut.

Tabel 7. Customer Satisfaction Index (CSI) Untuk Mengetahui Tingkat Kepuasan Konsumen Buah Durian di Kota Mataram

\begin{tabular}{|r|l|r|r|r|r|r|}
\hline No & \multicolumn{1}{|c|}{$\begin{array}{c}\text { Rata } \\
\text { Tingkat } \\
\text { Kepentingan } \\
\text { (MIS) }\end{array}$} & $\begin{array}{c}\text { Rata } \\
\text { Tingkat } \\
\text { Kinerja } \\
\text { (MSS) }\end{array}$ & $\begin{array}{c}\text { Weight } \\
\text { Factor } \\
\text { (MIS/ }\end{array}$ & $\begin{array}{c}\text { Weight } \\
\text { Score } \\
\text { (WF×MSS) }\end{array}$ & $\begin{array}{c}\text { CSI } \\
\text { Atribut }\end{array}$ \\
\hline 1 & Harga & 3.50 & 3.38 & 0.10 & 0.34 & 0.07 \\
\hline 2 & Ukuran & 3.83 & 3.58 & 0.11 & 0.40 & 0.08 \\
\hline 3 & Tekstur & 3.85 & 3.93 & 0.11 & 0.44 & 0.09 \\
\hline 4 & Aroma & 3.85 & 3.75 & 0.11 & 0.42 & 0.08 \\
\hline 5 & Cita Rasa & 4.40 & 3.95 & 0.13 & 0.51 & 0.10 \\
\hline 6 & Warna & 3.53 & 3.45 & 0.10 & 0.36 & 0.07 \\
\hline 7 & Kesegaran & 3.73 & 3.48 & 0.11 & 0.38 & 0.08 \\
\hline 8 & Kebersihan & 3.78 & 3.50 & 0.11 & 0.39 & 0.08 \\
\hline 9 & Jenis Durian & 3.80 & 3.50 & 0.11 & 0.39 & 0.08 \\
\hline & Jumlah & 34.25 & 32.50 & 1.00 & 3.62 & 0.72 \\
\hline
\end{tabular}

Sumber : Data primer diolah, 2019

Berdasarkan tabel 7 dari perhitungan nilai Weighted Score (WS) dibagi dengan skala 5 (skala penilaian). Total nilai WS seluruh atribut adalah 3.62 diperoleh dari hasil perkalian antara Weighted Factor (WF) dengan tingkat kinerja. Semakin tinggi nilai WS maka semakin tinggi juga kepuasan yang didapati dari kinerja atribut tersebut. Urutan atribut yang memiliki WS dari yang paling tinggi samapai paling rendah yaitu : cita rasa $(0,51)$, tekstur $(0,44)$, aroma $(0,42)$, ukuran $(0,40)$, jenis durian $(0,39)$, kebersihan $(0,39)$, kesegaran $(0,38)$, warna $(0,36)$ dan harga $(0,34)$. Atribut cita rasa memiliki WS paling tinggi yaitu 0,48 artinya tingkat kinerja terhadap atribut ini dinilai paling penting memenuhi harapan konsumen dibandingkan atribut lainnya. Sedangkan atribut yang memiliki WS paling rendah adalah atribut harga yaitu 0,34 artinya kinerja terhadap warna paling sedikit dibandingkan atribut lain. 
Nilai Weighted Factor (WF) adalah jumlah dari total rata-rata tingkat kepentingan dibagi dengan total rata-rata kepentingan seluruh atribut. Total dari nilai WF yang didapat adalah 1,00 . Berdasrkan perhitungan yang didapat atribut cita rasa memiliki nilai WF sebesar 0,13 , hal ini artinya dari total WF sebesar 1,00 atribut cita rasa mempengaruhi tingkat kepentingan sebesar 0,13 dari keseluruhan atribut. Atribut warna memiliki WF yang paling kecil dari keseluruhan atribut yaitu 0,10 , hal ini berarti atribut warna dan harga memiliki tingkat kepentingan yang rendah. Hubungan antara WF dan WS merupakan gambaran tingkat kepentingan dan kinerja atribut-atribut buah durian di Kota Mataram.

Berdasarkan hasil perhitungan nilai Costumer Satisfaction Index (CSI) dengan menggunakan skor rata-rata tingkat kepentingan dan tingkat kinerja, diperoleh nilai sebesar 0,72 atau sebesar $72 \%$. Index kepuasan konsumen tersebut berada pada kisaran 0.66 - 0.80, yang artinya bahwa secara keseluruhan konsumen buah durian merasa puas terhadap buah durian yang dibeli berdasarkan sembilan atribut pertimbangan dalam membeli buah durian.

\section{KESIMPULAN DAN SARAN}

\section{Kesimpulan}

Berdasarkan hasil penelitian dan pembahasan, maka dapat ditarik kesimpulan sebagai berikut: Berdasarkan hasil penelitian dan pembahasan, maka dapat ditarik kesimpulan sebagai berikut: (1) Perilaku konsumen dalam pembelian buah durian di Kota Mataram menunjukkan hasil yaitu 3,57 dalam arti konsumen kemungkinan akan membeli kembali buah durian tersebut, baik dilihat dari nilai sikap yaitu sebesar 3,65 berada pada interval skor positif dan norma subyektif yaitu sebesar 3,49 berada pada interval skor menganjurkan. Keputusan konsumen membeli di dominasi oleh atribut cita rasa karna cita rasa dari buah durian tersebut menjadi alasan utama dalam memutuskan pembelian dengan memiliki nilai evaluasi paling tinggi dibandingkan atribut lainnya dan motivas referen yang dipercayai oleh konsumen lebih mengikuti anjuran dari pihak keluarga. (2) Perilaku konsumen dalam pembelian buah durian di Kota Mataram berdasarkan karakteristik responden menurut pekerjaan, pendapatan dan suku/etnik rata-rata menunjukkan hasil yang positif dalam arti tidak adanya perbedaan perilaku konsumen dalam mengambil keputusan membeli buah durian di Kota Mataram (3) Kepuasan konsumen dalam pembelian buah durian di Kota Mataram termasuk dalam kategori tinggi dengan perhitungan Customer Satisfaction Index (CSI) sebesar 0,72 atau $72 \%$ termasuk dalam kategori bahwa konsumen merasa puas terhadap atribut-atribut buah durian berikut: harga, ukuran, tekstur, aroma, cita rasa, warna, kesegaran, kebersihan dan jenis durian, karena berada pada indeks antara 0,66 sampai 0,88. 


\section{Saran}

Berdasarkan hasil penelitian dan kesimpulan yang telah diuraikan, maka dapat diajukan saran yaitu : Bagi pelaku bisnis buah durian di Kota Mataram sebaiknya menyediakan buah durian yang sesuai pertimbangan utama pilihan konsumen seperti harga buah durian karna jika harga yang ditawarkan tinggi kemungkinan konsumen tidak mau membeli dan jenis durian yang disediakan karna bisa menentukkan cita rasa dari buah durian tersebut serta meningkatkan tingkat kepentingan dan kinerja yang sangat berpengaruh terhadap keputusan dan kepuasan konsumen dalam membeli buah durian agar dapat sepenuhnya mencapai indeks kepuasan 100\%; Meningkatkan atribut-atribut yang diyakini konsumen seperti cita rasa, aroma dan tekstur karna ketiga atribut tersebut paling mendominasi dan menjadi alasan utama yang sesuai dengan harapan konsumen, hal ini diharapkan mampu menarik minat konsumen agar tetap mau membeli buah durian; Untuk penelitian berikutnya diharapkan meneliti komoditi yang berbeda dan karakteristik responden manakah yang paling berpengaruh terhadap keputusan pembelian.

\section{DAFTAR PUSTAKA}

Ahira, A. 2011. Strategi Memenuhi Kepuasan Konsumen. https://www.anneahira.com . (Diakses pada 10 Februari 2019).

Ajzen, I dan Fishbein. 1980. Theory of Reasoned Action. Edisi Kesatu. Oleh Jogiyanto. Andi Publisher: Yogyakarta.

Redaksi Trubus. 2010. Lokasi Durian Lokal Enak . Cetakan ke-XLI. Penebar Swadaya: Jakarta.

Startford. 2004. Starford-on-Avon District Council Customer Satisfication Index June. Gramedia Pustaka Utama. Jakarta.

Sunyonto, D. 2014. Konsep Dasar Riset Pemasaran dan Perilaku Konsumen. Center For Academic Publishing Service. Yogyakarta.

Wildan. 2005. Panduan Survei Kepuasan. PT. Sucofindo. Jakarta. 